\title{
Mathematical modelling of sparkplug ignition of a coal-dust monodisperse suspension in a methane-air mixture
}

\author{
Alexey Yu. Krainov and Ksenia M. Moiseeva ${ }^{*}$ \\ Tomsk State University, Tomsk, 634050 Russia
}

\begin{abstract}
The paper provides the numerical simulation of a coal-dust monodisperse suspension sparkplug ignition in a methane-air mixture. The methane-air mixture is not stoichiometric. The aim of the research is a design-theoretical determination of the minimum ignition energy of coaldust-methane-air mixture (CDMAM) depending on the methane volume fraction. Simulation has shown that the increase of the methane volume fraction leads to the decrease of the CDMAM minimum ignition energy, and with the expansion of coal particles the minimum ignition energy rises.
\end{abstract}

\section{Introduction}

The research is devoted to sparkplug ignition of the coal-dust monodisperse suspension in a methane-air mixture. The solution to the problem provides applied data dealing with fire and explosion safety in coal industry. The research [1] describes the igniting mechanism and explosion in mines. It offers the explosion emerging scenarios and proposes assumptions of the influence the coal-dust content (particle size, mass content of reactive particles, and presence of the inert state) and reacting gas content (percentage of methane and impurities in the gas) on the possibility of the mixture to ignite.

The research [2] has drawn a conclusion about the ignition peculiarities and flame propagation in reacting gas mixture. The work provides research efforts of the coal-dust suspension explosive risk in air and in methane-air mixture. The reactive gas-coal dust-air mixture is capable of exploding under the low concentration of the coal dust. The paper [3] has shown theoretically that the coal dust burning in the volume becomes possible after the addition of a small amount of methane or after the heating of the volume walls.

The presence of the coal dust significantly effects the ignition characteristics of reactive mixtures. The minimum ignition energy of the coal dust depends on its mass concentration $[4,5]$. The "minimum sparkplug ignition energy-coal dust mass concentration" curve has been plotted in [5] and its minimum value has been determined. The work [6] defines the minimum energy dependence on the parameters of the coal dust. The gas suspension motion due to its heating has not been taken into account. The small particles decrease the minimum ignition energy. The larger particles increase the minimum ignition energy when the mixture is close to the stoichiometric condition, and decrease when the mixture is far

* Corresponding author: Moiseeva_KM@t-sk.ru 
from stoichiometric. The large particles do not influence the minimum ignition energy; it is equal to the mixture ignition energy. The researchers in [7] have investigated the problem of the thermal expansion influence on the minimum sparkplug ignition energy of the gas. According to the obtained results the thermal diffusion model of the gas sparkplug ignition energy decreases the value of the minimum energy more than two times.

\section{Mathematical model}

The monodisperse suspension of the coal dust is uniformly distributed in volume. The mass concentration of the coal dust is $m_{\text {dust }}$ and the methane volume concentration is $a_{C H 4}$. The mixture is not stoichiometric. The instantaneous filiform ignition source is located in the center of the volume. The outer boundary of the computational domain is supposed to be infinitely far from the ignition source. The diffusion and the heat transfer coefficients depend on the temperature [8]. There are two parallel reactions in the mixture, the first is the exothermic chemical reaction in the gas, and the second one is the heterogeneous reaction on the particle surface. The reaction rate in the gas is determined by the secondorder kinetics (the first-order kinetics for methane and the first-order kinetics for oxygen). The heterogeneous reaction rate is defined taking into account the diffusion of the oxidizer to the particle surface [9]. The chemical reaction rate constants depend on the temperature under the Arrhenius law. It is considered the interphase interaction between gas and particles. The electrode heat waste is neglected.

The mathematical model is based on the dual-velocity two-phase model of the reacting gas-dispersion medium [10]. The system of equations includes the mass-conversation equation, the impulse-conversation equation, the total energy-conversation equation of the gas and the particles taking into account the thermal conductivity and the chemical reactions in the gas and on the particle surface, the mass-conversation equation of the mixture gas components considering the diffusion and the combustion and the particle radius and concentration equations. The initial conditions were set in the same way as in [11].

The problem was solved numerically by S.K. Goduvov's method [12]. The summands on the right side of the gas energy-conversation equation and the oxygen mass balance equation, which determine the diffusion and the heat transfer processes, were explicit approximated by the three-point stencil. To solve the equations for the particle mass balance, the particle impulse-conversation and the particle energy-conversation the method from [13] was used. The time step was calculated by Courant's stability criterion. To verify the program code the adiabatic temperature after the explosion was calculated and compared with theoretical one, and the balance ratios were reviewed. The calculation error was equal to $0.03 \%$.

\section{Results and discussion}

The problem of the sparkplug ignition was solved under thermophysical and kinetics parameters of the coal dust taken from [8]. The dimension of the ignition energy was determined as $J / m$. To define the energy in $J$, the anode-cathode spacing should be taken into account, which is in the range of $4 \cdot 10^{-3}-6 \cdot 10^{-3} \mathrm{~m}$ [4].

Fig. 1 $(a, b)$ shows the minimum spark ignition energy - the methane volume fraction curves. The curve in fig. $1 \mathrm{~b}$ fairly agrees with the results in [4]. The distinction in the results is due to the absence of necessary data about coal dust dispersity. The fundamental result of the calculation corresponds to the data in [4] - the increase of the methane volume fraction in the mixture leads to the decrease of the minimum spark ignition energy of the 
CDMAM. For example, the $1 \%$ methane volume fraction in the coal dust suspension decreases the minimum spark ignition energy 5 times.

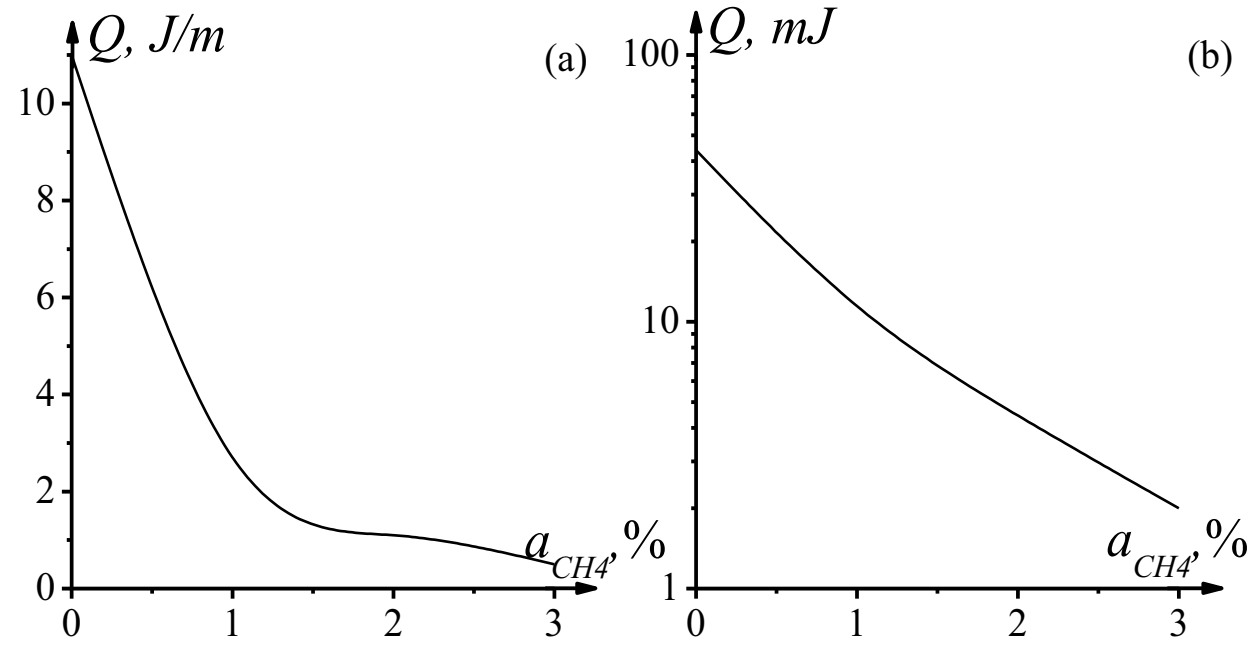

Fig. 1. The minimum spark ignition energy of CDMAM - the methane volume fraction curve. $m_{\text {dust }}=0.4 \mathrm{~kg} / \mathrm{m}^{3}, r_{k}=5 \cdot 10^{-7} \mathrm{~m}$. (a) -dimension $[\mathrm{J} / \mathrm{m}]$, (b) - the curve, when the anode-cathode spacing is $4 \cdot 10^{-3} \mathrm{~m}$
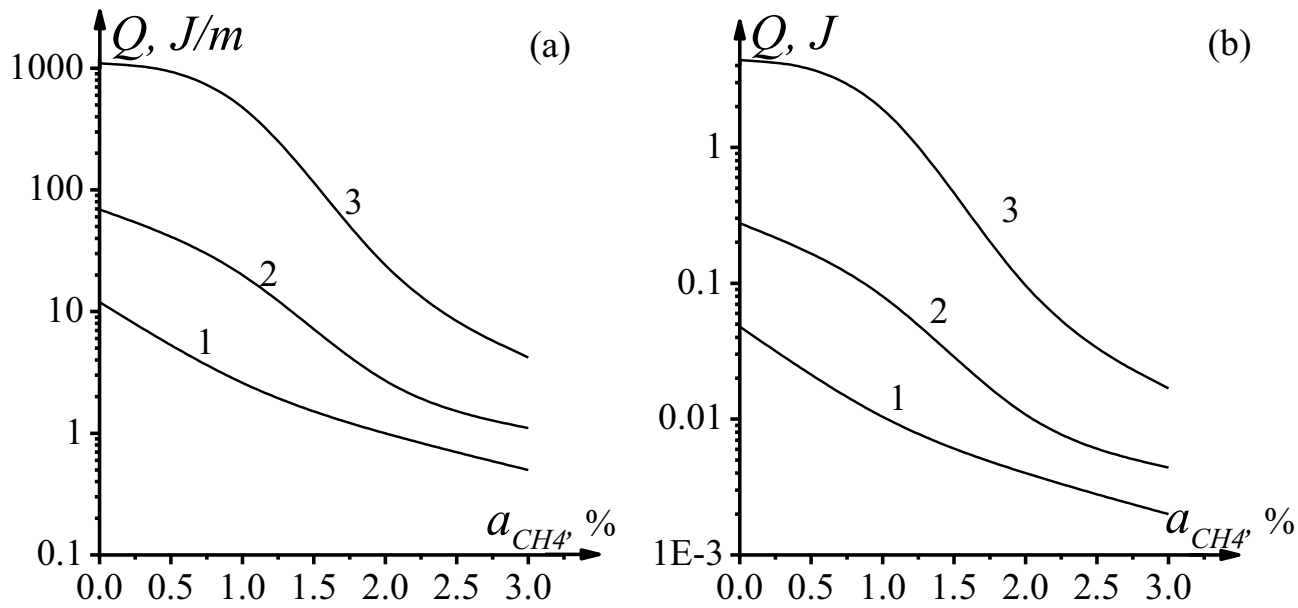

Fig. 2. The dependences of the minimum spark ignition energy of CDMAM on methane content in the mixture. $m_{\text {dust }}=0.4 \mathrm{~kg} / \mathrm{m}^{3}, \mathrm{rk}=5 \cdot 10-7 \mathrm{~m}$ (curve 1), $10^{-6} \mathrm{~m}$ (curve 2), $2 \cdot 10^{-6} \mathrm{~m}$ (curve 3). (a) dimension $[\mathrm{J} / \mathrm{m}],(\mathrm{b})$ - the curve, when the anode-cathode spacing is $4 \cdot 10^{-3} \mathrm{~m}$

The particle size of the coal dust influences the minimum spark ignition energy. The specific surface area decreases with the increase of the particle radius. The warm-up time of the particle rises. The ignition energy of the spark spreads in the gas during the warm-up time. The particles do not heat up to the inflammation temperature, the ignition does not appear. The calculation results of the particle size influence on the minimum ignition energy of CDMAM are presented in fig.2. The calculations were held for the particle radii: $r_{k}=5 \cdot 10^{-7} \mathrm{~m}, 10^{-6} \mathrm{~m}, 210^{-6} \mathrm{~m}$. With addition of the $1 \%$ methane volume fraction in the coal dust suspension the minimum spark ignition energy decreases 5, 3 and 1.1 times, respectively. The increase of the methane volume fraction leads to the decrease of the minimum ignition energy. 


\section{Conclusions}

The mathematical modeling of sparkplug ignition of CDMAM with low content of methane has been carried out. The influence of coal dust particle size and methane volume fraction on the minimum spark ignition energy has been obtained. The larger particles are the more energy is required to ignite the coal dust suspension in air or in the reactive gas. With the increase of the methane volume fraction in the mixture, the minimum ignition energy of the mixture with large particles decreases faster than for the mixture containing small particles.

This work was supported by the Russian Science Foundation grant No. 16-33-60091 mol_a_dk.

\section{References}

1. A.A. Vasil'ev, A.V. Pinaev, A.A. Trubitsyn, Combust., Expl., Shock Waves 53, 8 (2017)

2. S. Kalyakin, V. Kostenko, E. Zav'yalova and L. Shtrokh, Aktualne problemy zwalczania zagroźeń górniczych: II konferencja naukowo-techniczna (Brenna) 7-9, 176 (2012) [in Russian]

3. D. Bradley, M. Lawes, M.J. Scott, N. Usta, Combust. Flame 124, 82 (2001)

4. A.Ya. Korolchenko, Fire and explosion hazard of industrial dust (Moscow: Himija, 1986) [in Russian]

5. M.I. Neychlelyaev, A.I. Lyubimova, P.M. Petrukhin, Combating coal dust explosions in mines, (Moscow: Nedra, 1992) [in Russian]

6. A.Yu. Krainov, V.A. Baimler, Combust., Expl., Shock Waves 38, 30 (2002)

7. A.Yu. Krainov, V.A. Baimler, Combust., Expl., Shock Waves 38, 9 (2002)

8. A.Yu., Krainov, K.M. Moiseeva, JPCS 754, 052003 (2016)

9. D.A. Frank-Kamenetskiy, Diffusion and Heat Transfer in Chemical Kinetics (Moscow: Nauka, 1987) [in Russian]

10. R.I. Nigmatulin, Dynamics of Multiphase Media (CRC Press; 1990)

11. A.Yu. Krainov, Combust., Expl., Shock Waves 37, 16 (2001)

12. S.K. Godunov, A.V. Zabrodin, M.Ya. Ivanov, A.N. Kraiko, G.P. Prokopov, Numerical solution of multi-dimensional problems of gas dynamics (Moscow: Nauka, 1976) [in Russian]

13. A.N. Kraiko, J. Appl. Math. Mech. 43, 539 (1979) 